\title{
JOIN IRREDUCIBLE 2-TESTABLE SEMIGROUPS
}

\author{
EDMOND W.H. LEE \\ Department of Mathematics \\ Nova Southeastern University, FL 33314, USA \\ e-mail: edmond.lee@nova.edu \\ Dedicated to the 65th birthday of Professor Jorge Almeida.
}

\begin{abstract}
A nontrivial pseudovariety is join irreducible if whenever it is contained in the complete join of some collection of pseudovarieties, then it is contained in one of the pseudovarieties. A finite semigroup is join irreducible if it generates a join irreducible pseudovariety. The present article is concerned with semigroups that are 2-testable in the sense that they satisfy any equation formed by a pair of words that begin with the same variable, end with the same variable, and share the same set of factors of length two. The main objective is to show that there exist precisely seven join irreducible pseudovarieties of 2-testable semigroups. As a consequence, it is decidable in quadratic time if a finite 2-testable semigroup is join irreducible.
\end{abstract}

Keywords: semigroup, 2-testable, pseudovariety, join irreducible.

2010 Mathematics Subject Classification: 20M07.

\section{REFERENCES}

[1] P. Aglianò and J.B. Nation, Lattices of pseudovarieties, J. Austral. Math. Soc. Ser. A 46 (1989) 177-183. doi:10.1017/S1446788700030640

[2] J. Almeida, Finite Semigroups and Universal Algebra (World Scientific, Singapore, 1994).

doi: $10.1142 / 2481$

[3] S. Burris and H.P. Sankappanavar, A Course in Universal Algebra (Springer Verlag, New York, 1981).

[4] A. Escada, The G-exponent of a pseudovariety of semigroups, J. Algebra 223 (2000) $15-36$. doi:10.1006/jabr.1999.7993 
[5] T. Evans, The lattice of semigroup varieties, Semigroup Forum 2 (1971) 1-43. doi:10.1007/BF02572269

[6] M. Jackson, Finite semigroups whose variety has uncountably many subvarieties, J. Algebra 228 (2000) 512-535. doi:10.1006/jabr.1999.8280

[7] M. Jackson, Finiteness properties of varieties and the restriction to finite algebras, Semigroup Forum 70 (2005) 159-187. doi:10.1007/s00233-004-0161-x

[8] M. Jackson and E.W.H. Lee, Monoid varieties with extreme properties, Tran. Amer. Math. Soc. 370 (2018) 4785-4812. doi:10.1090/tran/7091

[9] E.W.H. Lee, Identity bases for some non-exact varieties, Semigroup Forum 68 (2004) 445-457. doi:10.1007/s00233-003-0029-5

[10] E.W.H. Lee, On a simpler basis for the pseudovariety EDS, Semigroup Forum 75 (2007) 477-479. doi:10.1007/s00233-006-0682-6

[11] E.W.H. Lee, Combinatorial Rees-Sushkevich varieties are finitely based, Internat. J. Algebra Comput. 18 (2008) 957-978. doi:10.1142/S0218196708004755

[12] E.W.H. Lee, On the variety generated by some monoid of order five, Acta Sci. Math. (Szeged) 74 (2008) 509-537.

[13] E.W.H. Lee, Combinatorial Rees-Sushkevich varieties that are Cross, finitely generated, or small, Bull. Aust. Math. Soc. 81 (2010) 64-84. doi:10.1017/S0004972709000616

[14] E.W.H. Lee, Finite basis problem for 2-testable monoids, Cent. Eur. J. Math. 9 (2011) 1-22. doi:10.2478/s11533-010-0080-x

[15] E.W.H. Lee, Varieties generated by 2-testable monoids, Studia Sci. Math. Hungar. 49 (2012) 366-389. doi:10.1556/SScMath.49.2012.3.1211

[16] E.W.H. Lee, J. Rhodes and B. Steinberg, Join irreducible semigroups, Internat. J. Algebra Comput. 29 (2019) 1249-1310. doi:10.1142/S0218196719500498

[17] E.W.H. Lee and M.V. Volkov, On the structure of the lattice of combinatorial ReesSushkevich varieties, in: Semigroups and Formal Languages (Lisbon 2005), André, Fernandes, Branco, Gomes, Fountain and Meakin (Ed(s)), (World Scientific, Singapore, 2007) 164-187. doi:10.1142/9789812708700\_0012 
[18] E.W.H. Lee and M.V. Volkov, Limit varieties generated by completely 0-simple semigroups, Internat. J. Algebra Comput. 21 (2011) 257-294. doi:10.1142/S0218196711006169

[19] S.A. Malyshev, Permutational varieties of semigroups whose lattice of subvarieties is finite (in Russian), in: Modern Algebra, (Leningrad. Univ., Leningrad, 1981) $71-76$.

[20] J. Rhodes and B. Steinberg, The $q$-theory of Finite Semigroups, Springer Monographs in Mathematics (Springer, Berlin, 2009). doi:10.1007/b104443

[21] M.V. Sapir, Problems of Burnside type and the finite basis property in varieties of semigroups, Math. USSR-Izv. 30 (1988) 295-314. [Translation of Izv. Akad. Nauk SSSR Ser. Mat. 51 (1987) 319-340.] doi:10.1070/IM1988v030n02ABEH001012

[22] A.N. Trahtman, Some finite infinitely basable semigroups (in Russian), Ural. Gos. Univ. Mat. Zap 14 (1987) 128-131.

[23] A.N. Trahtman, A six-element semigroup that generates a variety with a continuum of subvarieties (in Russian), Ural. Gos. Univ. Mat. Zap 14 (1988) 138-143.

[24] A.N. Trahtman, Identities of a five-element 0-simple semigroup, Semigroup Forum 48 (1994) 385-387. doi:10.1007/BF02573687

[25] A.N. Trahtman, Identities of locally testable semigroups, Comm. Algebra 27 (1999) 5405-5412. doi:10.1080/00927879908826762

[26] B.M. Vernikov and M.V. Volkov, Lattices of nilpotent varieties of semigroups. II (in Russian), Izv. Ural. Gos. Univ. Mat. Mekh. 1 (10) (1998) 13-33.

[27] M.V. Volkov, The finite basis question for varieties of semigroups, Math. Notes 45 (3) (1989) 187-194. [Translation of Mat. Zametki 45 (3) (1989) 12-23.] doi:10.1007/BF01158553

Received 4 December 2019

Revised 3 July 2020

Accepted 3 July 2020 